\title{
MEMORIAL SOBRE A TRAJETÓRIA ESCOLAR BÁSICA DE GILVÂNIA MARA DOS SANTOS MATOS
}

\author{
Gilvânia Mara dos Santos Matos ${ }^{1}$
}

Resumo: O presente texto trata do memorial sobre a trajetória escolar de Gilvânia Mara dos Santos Matos, ex-integrante do Programa Conexões de Saberes. Tem como objetivo apresentar os passos percorridos desde o início da educação básica até a entrada à UFPA e quais os principais entraves de estudantes das comunidades populares adentrarem o ensino superior público. A memória foi usada como principal referência para construção do material. Em seus resultados, apresenta os esforços individual e coletivo para que de fato a educação seja uma questão de direito e não de privilégio de poucos.

Sou Gilvânia Mara dos Santos Matos, nasci na cidade de Castanhal, no Pará, em 06 de maio de 1987. Sou fruto do segundo casamento do meu pai (35 anos) com uma adolescente (15 anos). Desse casamento sou a terceira filha, totalizando cinco filhos. O clima sempre foi tenso, meus pais não se entendiam, pois meu pai sofria de uma patologia chamada alcoolismo. Não se estabilizava em emprego algum, agredia minha mãe, quebrava objetos e era comum dormirmos na casa de vizinhos e parentes. Para garantir nossa sobrevivência, minha mãe começou a alfabetizar crianças em nossa casa, também a auxiliávamos nessa tarefa.

No fim tudo dá certo, se não deu certo é porque ainda não chegou ao fim $^{2}$

Ingressei na escola aos 07 anos de idade, não fui alfabetizada. Fiz a primeira série com muito sucesso, ou seja, para quem nunca havia estudado, passar de ano era reflexo de muito esforço e dedicação. Esse foi um momento de descoberta e admiração, pois com muita dificuldade, problemas, sem o apoio familiar, consegui sobressair nos estudos. A partir daí, escutei muitas frases de incentivo, que ajudaram a me dedicar mais e mais.

Sempre fui reservada, dada toda a realidade que me rodeava. Minha mãe era muito exigente e radical; meu pai, sempre acomodado, estava desempregado e achava que tudo estava em perfeita harmonia. Isso me indignava, eu ficava horas me perguntando o por quê de todos os pais trabalharem e o meu não, será que eu e meus quatro irmãos já estávamos criados como eles diziam estar?

\footnotetext{
${ }^{1}$ Graduada em Letras pela Universidade Federal do Pará, e-mail: a_gilvania@yahoo.com.br

${ }^{2}$ Esses pensamentos que estão em negrito no decorrer do texto foram retirados de uma agenda que foi escrita por amigas e colegas da época do ensino médio.
} 
$\mathrm{Na}$ sala de aula, eu era uma aluna meiga, calada, calma, mas quando falava a classe toda ria, uma vez que dizia coisas muito ingênuas e utópicas. Minhas amigas eram muito conformistas. Já tinham suas opiniões formadas sobre a vida, acreditavam que tudo era com era e não tinha como mudar/melhorar. Mas eu era do contra, nunca me achei naquele mundo, nem me encontrava naquelas idéias.

O tempo foi passando e os meus sonhos cresceram cada vez mais. Quanto mais as pessoas tentavam DETERMINAR meu destino (diziam que eu seria um mero produto do meio: vendedora de lojas, dona de casa, doméstica), mais provava o contrário; queria ser diferente, queria fazer o que ninguém havia feito antes na minha família. Quando algum grupinho da classe ficava reunido conversando sobre shows/roupas/marca de cadernos/sapatos, não argumentava nada, pois isso não fazia parte do meu mundo. Fui crescendo e as necessidades também. Logo, comecei a ter desejos materiais, pessoais e espirituais como qualquer ser humano.

\section{INCENTIVOS}

Meus professores me olhavam com carinho e viam em mim uma pessoa esforçada. Então ouvi pela primeira vez as palavras PSS (Processo Seletivo Seriado), PRISE (Programa de Ingresso Seriado), e vestibular. Nesse momento, lembro, as dúvidas sobre essa novidade começaram a surgir dentro de mim, queria saber mais, queria saber tudo, quais as chances/possibilidades de me tornar tudo aquilo que a academia prometia. Poxa! Fui alucinada para casa, a alegria era imensa, pois mais uma vez me projetava para o futuro, projeção esse que exigiria muita luta, garra e determinação.

É a partir desse momento que minha amizade da bandeirinha, do tacobol, da fichinha, dos igarapés, do anelzinho, do cai no poço, começou a diminuir. O comprometimento com os estudos era tamanho que minhas colegas iam em minha casa constantemente (de manhã, de tarde e de noite) e eu estava estudando do mesmo jeito. Resultado: o vínculo de amizade, a rotina constante de lazer chegou ao ponto de acabar e ficarmos só no oi. Em casa ninguém me entendia, vivia isolada e estudando.

Para estudar não bastava só querer, havia condições impostas, primeiro cuidar dos afazeres domésticos, porém isso não me freou, apenas passei a dormir mais tarde e acordar mais cedo, tudo isso para cumprir todo cronograma que pré-estabeleci para a casa e para os estudos. 


\section{A IGREJA COMO FORÇA, APOIO E DESINIBIÇÃO}

Assim como a FAMÍLIA e a ESCOLA são importantes para nossa educação, sinto que o grupo da igreja foi determinante no auxílio de minha formação. Lá era o único lugar onde todos me entendiam, tudo que fazia era bem vindo, admirado. Nesse ambiente me sentia livre e autônoma. Isso influenciou diretamente na sala de aula, os conteúdos começaram a fluir melhor, meus seminários eram um sucesso, tornei-me uma aluna comunicativa, expressiva e com opinião própria.

\section{RESPONSABILIDADE PRECOCE}

Aos doze anos de idade chamaram-me para substituir uma secretária (minha mãe) do grupo da igreja (Legião de Maria - um grupo da Igreja Católica, composta por pessoas adultas) que havia entregado o cargo antes do tempo previsto (três anos). Provisoriamente aceitei, mas todos gostavam da minha dedicação e me convidaram para ser a próxima secretária. Pensei logo no esforço e atenção que seriam cobrados de mim, a vontade de continuar foi maior do que meu pensamento, e sem perceber já estava totalmente envolvida nas atividades da igreja. Cada dia/ano que passava estava mais e mais comprometida.

Muitas coisas começaram a fazer parte da minha vida, algumas por afinidades outras por extrema necessidade, como trabalho. A situação financeira da família nunca se estabilizava. Como minha mãe alfabetizava crianças em casa, comecei fazer o mesmo. Os motivos foram pessoais, queria ajudar minha família, queria comprar todas as minhas apostilas, meu uniforme, ter meu dinheiro, autonomia.

\section{Nunca se esqueça que: \\ Para toda noite há um dia \\ Para todo tema um poema \\ Para todo caminho há uma porta \\ Para toda ida há uma volta \\ Para toda lágrima há um sorriso \\ Para todo abandono um abrigo \\ Para todo erro uma chance \\ Para tudo há um limite \\ Para todo mal um final. \\ Você é sempre \\ Especial \\ (Luciene Nunes)}


Tempos difíceis, muito trabalho, estudos, serviço comunitário e afazeres domésticos. Mas ainda encontrava tempo para dar uma volta na praça e ver o primeiro namoradinho, eu ficava dias e dias só esperando por esse momento, passava horas e horas falando dele para minhas amigas e vice-versa, muitas vezes o assunto era tanto que nem conseguíamos estudar, falamos a aula toda. As minhas primeiras amigas inseparáveis foram a Simone, a Monica e a Luciene. Para não perdermos o vínculo, combinávamos horários e turma que iríamos estudar. Ah! Sem falar que eu e a Mônica éramos apaixonadas pela mesma pessoa, emprestávamos roupas, maquiagem, dormia na casa dela... Tempos depois nós ficamos com a mesma pessoa (só fiquei com o rapaz depois que eles acabaram, ela ficou surpresa quando nos viu juntos).

\section{O ÁPICE DO NOSSO VÍNCULO DE AMIZADE}

Essa fase foi muito boa, pois estávamos na adolescência (normalmente nossos pais tentam nos super proteger e vêem perigo em tudo), época de conflitos, puxões de orelha, de ser chamada atenção constantemente, de chegar tarde em casa e de dormir escutando esculhambação... O primeiro pensamento que vinha na minha cabeça nessas horas era: não fiz nada demais, por que a mamãe briga tanto comigo? Sou consciente, sei dos meus limites, sei o que é e o que não é conveniente para mim, por que ela se preocupa? No entanto, sabia também do meu dever de começar fazer algo pensando no futuro, porém o futuro ainda estava tão distante, por que pensar nele? Queria era me divertir.

Nossa maior diversão ficou por conta dos bingos proporcionados pela escola, dançava tanto que no outro dia só ouvia os comentários na sala de aula. A única festa que eu ia era na escola, a Mônica e a Simone iam para outras em Castanhal, lá conheceram seus respectivos maridos, hoje elas são mães. A família da Luciene, ameaçada de morte, foi embora do bairro sem se despedir, para Parauapebas, e lá ela faleceu de uma apendicite estourada.

Depois de 07 anos (de 12 a 19 anos) como secretária da igreja, não estava mais dando conta e entreguei, com muita resistência por parte do grupo, o meu cargo.

\section{Se queres o que não tens, faças o que não fez.}

No último ano do ensino médio, não estava fazendo nem o PRISE, nem o PSS, pois na época das inscrições não tinha dinheiro. O primeiro semestre se passou e eu estava estudando apenas para concluir. Quando retornei das férias de julho, ouvi um comentário que iria abrir 
inscrição para um cursinho popular Projeto Cabano e que as aulas iniciariam no dia 15 de agosto de 2004. Interessei-me; minhas novas amigas também. Sem pedir permissão para meus pais me inscrevi. Na sexta-feira disse para meus pais que iria fazer cursinho (eles nem sabiam o que era isso), que era de segunda a sexta das 19:00h às 22:00h; aos sábados, de manhã e de tarde; aos domingos, pela manhã; nos feriados, de manhã e de tarde e possivelmente corujões; eles entraram em choque! Minha mãe implicava/brigava porque deixava os afazeres domésticos para estudar. Tinha horas que estudava chorando de raiva. Ah! Como nem todo dia tinha o dinheiro da passagem, eu faltava em muitas aulas, às vezes meu pai separava o dinheiro do transporte, a mamãe ia e gastava, dizia que eu só ia passear no centro da cidade.

O Projeto Cabanos foi um cursinho que marcou minha vida. Vivia admirando meus professores, me espelhava neles e queria ser igual a eles. Além de repassar conteúdos, eles transmitiam também força e incentivos.

Rotina: manhã - ministrar aulas para vinte e oito crianças; tarde - estudar o ensino médio; noite - cursinho. Nessa época, não me alimentava direito. A pendência da escola, trabalho individual e coletivo fazia quando chegava do cursinho, era comum dormir após meia-noite.

Adaptei-me, e só sonhava com minha aprovação. Chegou o período da inscrição no vestibular, no valor de $\mathrm{R} \$ 70,00$ (setenta reais); mais um desafio, pois veio em um momento difícil. O prazo estava se esgotando. No momento vivíamos um período de campanha eleitoral; preocupada, minha mãe sugeriu que pedisse o valor para um candidato, não gostei, mas foi um único jeito. Fui lá, falei, ele disse que daria a mim a quantia, retornei no dia combinado e ele falou que a verba ainda não tinha chegado (depois nem me dava atenção). Meus pais comoveram-se e nós resolvemos trabalhar como boca de urna no dia da eleição, no final do dia estava com o dinheiro em mãos, o próximo passo era escolher a área. No cursinho não tivemos palestras que apresentassem cada curso, o que se faz neles e o que significam... e mesmo que houvesse, minha decisão seria a mesma. A minha opção partiu da conveniência, da lógica e da afinidade. A faculdade de Letras era o que almejava, já que atuava na área, queria estudar para tornar uma profissional qualificada e reconhecida, me tornar financeiramente estável para ajudar minha família; sem falar que para estudar não iria ter gastos com passagens, pois a universidade é localizada no bairro onde moro. 


\section{O VESTIBULAR}

Já havia prestado as três etapas do processo, o conceito obtido por mim foi bom, porém não tinha certeza da aprovação. O interessante é que eu pensava positivo a todo instante, e os preparativos para a festa a cada dia aumentavam mais na prateleira da cozinha, o dinheiro da carne para o churrasco estava reservado debaixo do meu colchão. Na minha igreja o diácono, os membros do grupo priorizavam a minha aprovação em suas preces, eles foram provas vivas de todo meu esforço e viram o quanto isso me consumiu.

Era sexta-feira, acordei, fui para sala de aula, trabalhei. Poucas horas antes de acabar a aula minha prima ouviu meu nome no listão dos aprovados. Ela chegou na minha casa toda empolgada e contagiou todos com a notícia da minha vitória; abracei minha mãe e nós nos emocionamos. Eu e minha prima fomos imediatamente para o cursinho comemorar com os outros, mas ao chegar lá constatei que apenas eu havia passado. A festa foi exclusiva para mim, meus professores todos me abraçaram e desejaram muita sorte e sucesso.

\section{Alô! Alô! Alô, papai. Alô, mamãe! \\ Ponha a vitrola pra tocar, podem soltar foguetes (...)}

Quando chegamos em casa minha mãe já tinha contado para toda vizinhança e convocado todos para ajudar no almoço; ela estava muito orgulhosa de mim. Quebrei um tabu, pois dizem que para entrar na faculdade temos que estudar anos e anos de cursinho (só estudei seis meses), que só quem passa é filho de rico, que filho de pobre só estuda até o ensino médio. A minha vitória compartilhei com os meus amigos, que me jogaram muitos ovos, derramaram trigo, café e colorau, fiquei o dia todo suja. Guardo lembranças muito boas desse dia. Passava um filme na minha mente; ser vitoriosa é muito bom, mudar também é ótimo. Porém as pessoas temiam uma mudança da minha parte, porque ouvi frases como agora é outra Gilvânia e vê se não esquece de nós.

\section{Se em teu caminho encontrares pedras, e essas ferirem teus pés, lembre que outros também passaram por aí, nem por isso deixaram de caminhar.}




\section{HOJE}

Como fruto do cursinho Projeto Cabanos senti a necessidade de retornar ao mesmo como professora de literatura, queria contribuir para que outras pessoas relizem seus sonhos assim como eu. Lá me sentia respeitada e feliz pelo novo trabalho. Na faculdade, novas amizades, estudos constantes, afirmação da minha identidade e pensamentos começavam fazer parte do meu mundo. Chegou um tempo que os compromissos com os trabalhos acadêmicos estavam exigindo ainda mais de mim e resolvi sair do projeto.

Atualmente, com muito amor, protagonizo ações sociais em minha comunidade, sou professora em um cursinho popular próximo à minha casa. Com a benção de Deus estou firme e forte no meu objetivo de contribuir para a realização dos sonhos de outras pessoas; a minha alegria é saber que sou espelho para muitos outros jovens que estavam sem perspectivas. 